\title{
Hospital cognitive screening of patients with no related complaints
}

\section{Rastreio cognitivo em ambiente hospitalar de pacientes}

\section{sem queixas relacionadas}

Kelly da Silva(1)

Maria Edna Almeida Chaves ${ }^{(1)}$

Patrícia Aparecida Zuanetti(2)

Rodrigo Dornelas ${ }^{(1)}$

Raphaela Barroso Guedes-Granzotti(1)

\footnotetext{
Departamento de Fonoaudiologia da Universidade Federal de Sergipe-UFS, Campus Prof. Antônio Garcia Filho, Lagarto/SE, Brasil.

(2) Hospital das Clínicas da Faculdade de Medicina de Ribeirão Preto da Universidade de São Paulo, Ribeirão Preto/SP, Brasil.

A study conducted at the Departamento de Fonoaudiologia da Universidade Federal de Sergipe-UFS, Campus Prof. Antônio Garcia Filho, Lagarto/SE, Brasil.
}

Conflict of interest: non-existent

Received on: February 03, 2017 Accepted on: July 04, 2017

Mailing Address:

Raphaela Barroso Guedes-Granzotti Departamento de Fonoaudiologia

Rua Laudelino Freire, $n^{0} 184,2^{\circ}$ andar -

Centro, Lagarto, Sergipe, Brasil

CEP: $49000-000$

E-mail: raphaelabgg@gmail.com

\section{ABSTRACT}

Purposes: to characterize the cognitive performance hospitalized adults and elderly patients with no complaints, check the effect of education and age and correlate the results.

Methods: cognitive screening was carried out by the Mini Mental State Examination (MEM) and the Verbal Fluency Test, semantics (FVS) and phonological (FVF) in 25 adults and elderly with no cognitive changes complaints admitted in an internal medicine ward. For statistical analyses, the one-way Anova, followed by post hoc Tukey, the bivariate Person correlation and the nonparametric Fisher's tests were used.

Results: a high frequency of cognitive impairment and a moderate correlation among the three tests applied were verified. The educational factor influenced the results of the MEM, the FVF and FVS tests, while the age factor significantly influenced the evidence of MEM and FVS.

Conclusion: the data demonstrated that cognitive screening in hospitalized patients without related complaints is important, and that age and education are paramount factors in cognitive performance.

Keywords: Cognition; Age Groups; Education Status; Memory; Hospitals

\section{RESUMO}

Objetivos: caracterizar o desempenho cognitivo de adultos e idosos hospitalizados, sem queixas, considerando 0 efeito da escolaridade e da idade, e correlacionar os resultados encontrados.

Métodos: foi realizado rastreio cognitivo por meio do Miniexame do Estado Mental (MEM) e do Teste de Fluência Verbal, semântica (FVS) e fonológica (FVF), em 25 adultos e idosos sem queixas de alterações cognitivas internados em uma enfermaria de clínica médica. Para as análises estatísticas foi utilizado 0 teste Anova one way, seguido do teste Post Hoc de Tukey, do teste de correlação bivariada de Pearson e do teste exato de Fisher (não paramétrico) para associação dos resultados.

Resultados: evidenciou-se alta frequência de alterações cognitivas e correlação moderada entre os três testes aplicados. 0 fator escolaridade influenciou os resultados do MEM, do Teste de FVF e FVS, enquanto o fator idade influenciou significantemente apenas as provas de MEM e FVS.

Conclusão: os dados demonstram a importância do rastreio cognitivo em pacientes hospitalizados sem queixas relacionadas e, que a idade e a escolaridade são fatores importantes no desempenho cognitivo.

Descritores: Cognição; Grupos Etários; Escolaridade; Memória; Hospitais 


\section{INTRODUCTION}

There are many variables related to the maintenance of autonomy and quality of life in adults and, especially, in the elderly. The investigation of these variables, as well as studies on the prevention and treatment of disorders that influence the independence of these individuals, have grown significantly in the last years, with emphasis on cognition. This occurs since the quality of the cognitive structure is necessary to favor self-sufficiency in the daily activities ${ }^{1,2}$.

In order to identify cognitive abilities, some tests can be applied, either individually, serving for the screening of the identification of cognitive deficits or composing more complex and comprehensive tests ${ }^{3-5}$. Most screening tests for dementia can be divided into cognitive tests, performed directly with the patient; and functional assessments, which can be performed both with the patient or their relatives or caregivers as informants ${ }^{6}$.

Since its publication ${ }^{7}$, the Mini Mental State Examination (MEM) has become one of the most important and widespread tools to identify clinical changes in cognitive status in geriatric patients. It is used to track cognitive changes, to monitor evolutionary diseases involving cognition and the results of treatments performed. However, it can not be used to diagnose dementia ${ }^{8,9}$.

Studies also indicate that it can be used as a single instrument for screening, but it is ideally associated with tests, such as the Verbal Fluency Test (VFT), used for screening executive and language functions ${ }^{10}$. This is because changes in executive functions are not as well evaluated in the MEM and are present in several cases of dementia syndrome, as an initial - and often almost exclusive - manifestation. The evaluation of verbal fluency is usually employed to investigate lexical evocation skills and semantic knowledge; also allowing the evaluation of other cognitive functions, such as attention, long-term memory, mental flexibility, capacity to inhibit responses and mental processing speed ${ }^{11-14}$.

Therefore, in those patients with a doubt about the presence of mild cognitive decline, whether it is a very early dementia or a mild cognitive impairment, the combined use of these tests is recommended. In addition, the MEM and the VFT are instruments of rapid application and with previous studies in the Brazilian population ${ }^{10-16}$.

It is necessary to consider that several diseases can occur with cognitive alterations at some point in their evolution, however, these changes often are not perceived by patients and relatives and, as a consequence, they are not reported to health professionals, making it difficult to achieve an early diagnosis ${ }^{17,18}$.

As described and, knowing that cognitive evaluation is still usually reserved for patients with complaints in this sphere, the objective of the present study was to evaluate adults and elderly hospitalized in a medical ambulatory without cognitive complaints and to correlate the results of the MEM and the VFT Test, considering the effect of schooling and age on the results.

\section{METHODS}

The research followed the ethical recommendations of resolution 496/2012 of the National Health Council of the Ministry of Health for studies with human beings and was approved by the research ethics committee of the Federal University of Sergipe - UFS under the 29046414.0.0000.5546 CAAE number. All the participants signed the Free and Informed Consent Term, authorizing their participation in the research.

It is an observational, analytical and cross-sectional study of 25 individuals, 14 men and 11 women, hospitalized in the Medical Clinic ambulatory of a regional hospital in the interior of the state of Sergipe. The inclusion criteria were: age above 18 years old, absence of complaints related to cognitive alterations and length of hospital stay for a period longer than 24 hours. The exclusion criteria were: patients included in the medical record that presented a lowered level of consciousness, patients with diseases that prevented the application of the test, patients sedated or taking sedatives up to 4 hours before the test and individuals who had been discharged before the end of the test application or who gave up during the survey.

Data collection was performed from an anamnesis, containing questions about participant identification data and their health history, with the application of the MEM and the Verbal Fluency (VF) Test.

The applied version of the MEM was the proposal adapted by Brucki et al. ${ }^{8}$, who evaluated the performance in the MEM regarding schooling and obtained the following values for the 25th percentile, adjusted for schooling (illiterate: 17,1 to 4 years: $23 ; 5$ to 8 years: 25; 9 years or more: 27). Also according to Vitiello et $\mathrm{al}^{15}$, the following cut-off scores were considered: $<18$ for illiterates, $<21$ for individuals with 1 to 4 years of schooling, $<24$ for 5 to 8 years, and $<26$ for those with educational attainment above 8 years. 
The VF test was divided into the Phonological Verbal Fluency (FVF) and Semantic Verbal Fluency (FVS) tests. In the $\mathrm{FVF}^{19}$ test, the patient was asked to issue as many words as possible, starting with letter A, in one minute. In the $\mathrm{FVS}^{12}$ test, the patients were asked to issue animal names for one minute. The emission was recorded, enabling the counting of the number of words per minute and, for general analysis, the number of words emitted per blocks of 15 seconds was counted. For the classification of the results in 'normal' or 'altered', we considered the values obtained in the studies of Brucki et al. (1997) ${ }^{16}$ and Rodrigues et al. (2008) ${ }^{20}$, for FVS and FVF, respectively.

In order to verify the influence of the educational variable on the results found, the participants were divided into illiterate; with one to four years of study; and five or more years of study. To study the influence of age, the individuals were separated regarding their age group: 26-49 years old, 50-65 years old and $>66$ years of age.

The data were tabulated in an Excel spreadsheet (Microsoft ${ }^{\circledR}$ Office package) for descriptive analysis and processed by the SPSS ${ }^{\circledR} 15.0$ for Windows. For statistical analysis, the Kolmogorov-Smirnov test was used to verify the normality of the data. The one-way Anova test, followed by the Tukey Post Hoc, the Student's T-test for independent samples, the Pearson's bivariate correlation test and the Fisher's exact test (non parametric) were used for association of the results found. A significance level of $5 \%$ ( $p$ value $<0.05$ ) was considered.

\section{RESULTS}

The average age of the participants was 58.3 years old (SD \pm 17.5). Eight (32\%) were between 26 and 49 years old; seven (28\%) aged between 50 and 65 years old and ten (40\%) were over 66 years of age.

Regarding schooling, 10 individuals (40\%) were illiterate, eight (32\%) studied from one to four years and seven $(28 \%)$ studied five years or more.

Regarding the reason for hospitalization, eight (32\%) had gastrointestinal or urinary problems, seven (28\%) presented cardiorespiratory changes and ten (40\%) were hospitalized for several other reasons.

The overall average of MEM was 19.2 points (SD \pm 6.7). The average of FVS was 12.8 (SD \pm 6.3 ), with FVF being 7.6 ( $\mathrm{SD} \pm 7.7$ ). According to the KolmogorovSmirnov test, the sample was considered with normal distribution for these findings ( $p>0.05$ ).

Figure 1 shows the overall average number of evoked words every 15 seconds, in both the FVS and FVF tests. The T-Student test for independent samples identified a significant difference between the FVS and FVF scores when comparing the average number of words evoked during 15-30 seconds and 45-60 seconds ( $p<0.01$ and $p=0.02$, respectively).

Figures 2 and 3 illustrate the average score of the participants according to their schooling and age, respectively.

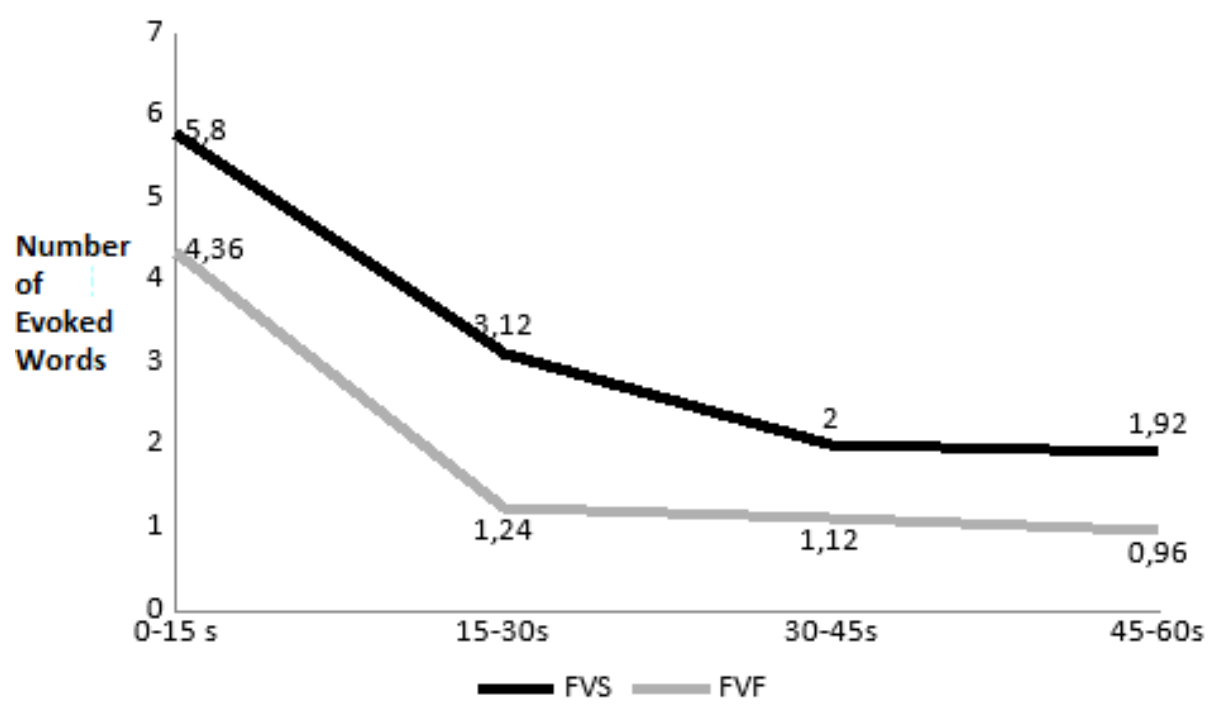

Subtitle: The symbols * and \# indicate $p<0.05$ identified by the independent T-test, in the second and in the fourth time block, respectively

Figure 1. Number of words evoked every 15 seconds in FVS and FVF tests throughout the sample. 


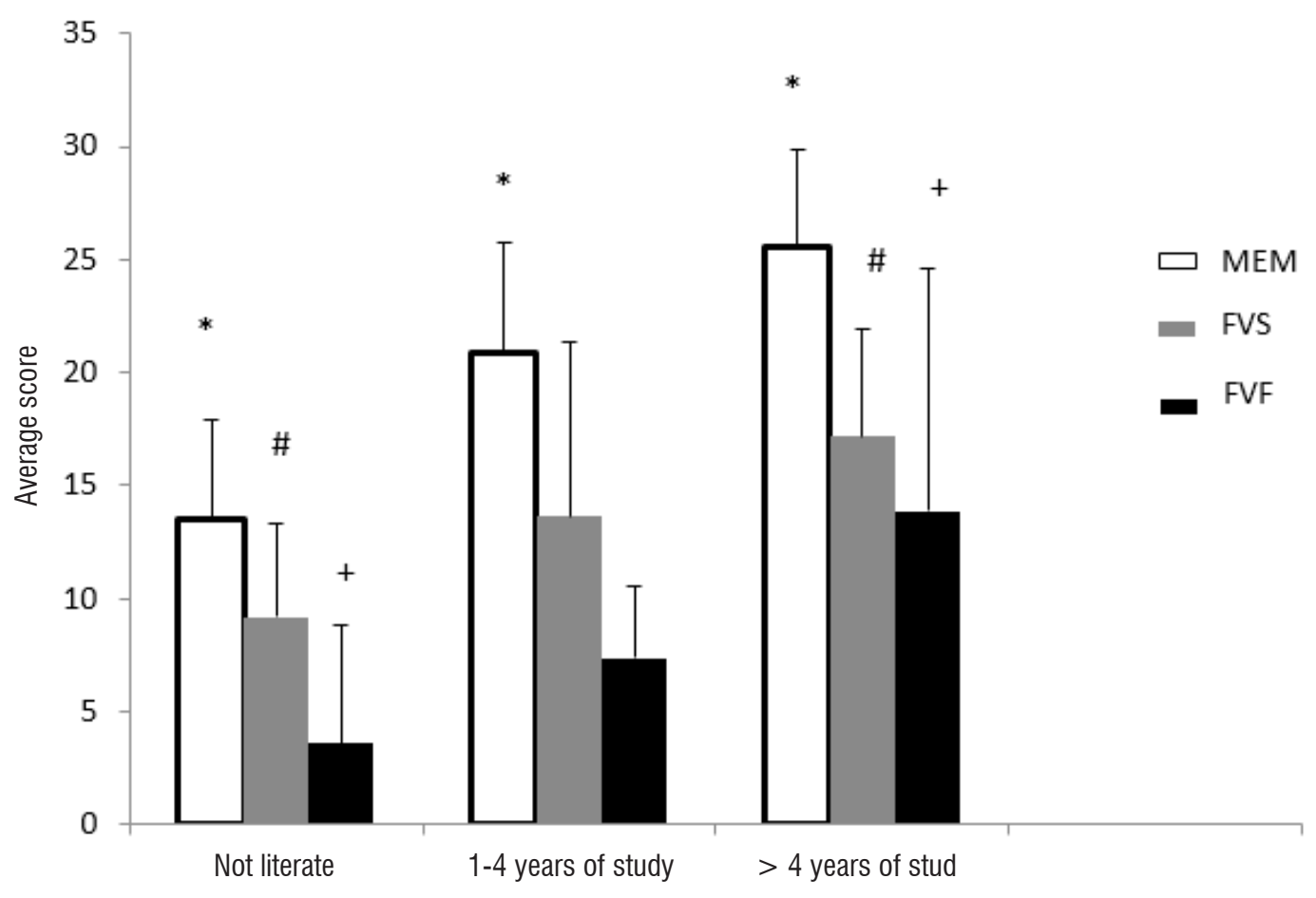

\section{Average score}

Subtitle: the symbol * represents $p<0.05$ between individuals without literacy and the other study groups in the MEM. The symbols \# and \& indicate $p<0.05$ when comparing the group of people without literacy with people over 4 years of study. The One-Way ANOVA test, followed by the Tukey Post-Hoc test, was used.

Figure 2. Average score of the participants, according to schooling, in the MEM, in the FVS and FVF tests.

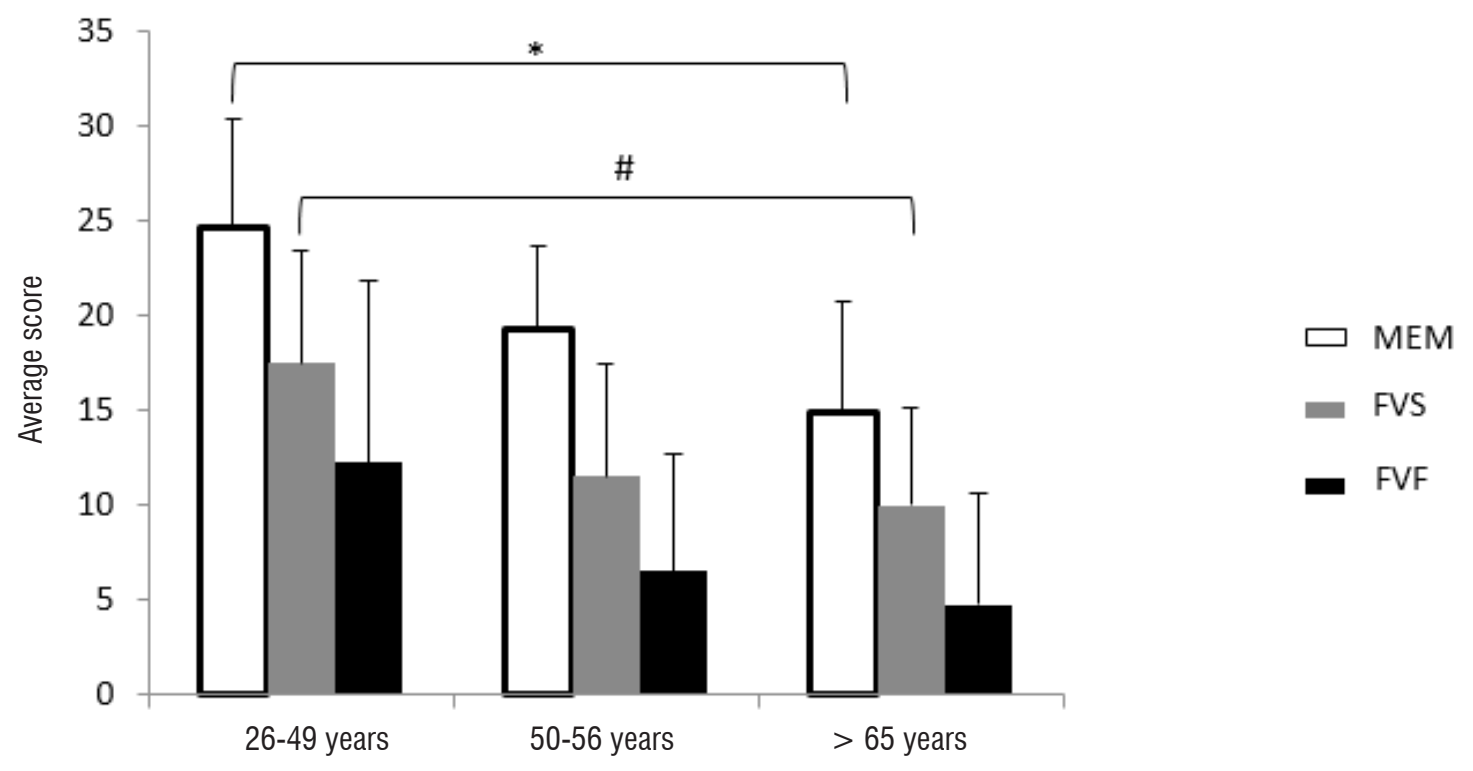

Subtitle: The symbol * and \# indicate $p<0.05$ according to the Anova test, followed by the Tukey Post Hoc, between individuals aged between 26 to 49 years old and individuals over 65 years, in the MEM and in the FVF, respectively.

Figure 3. Average score of the participants, according to age, in the MEM, in the FVS and FVF tests. 
Pearson's test evidenced a strong correlation when comparing the MEM with FVS $(R=0.76, p<0.01)$ and with FVF $(R=0.71, p<0.01)$. A moderate correlation was presented when comparing FVF with FVS $(R=0.60, p<0.01)$. The Fisher's exact test showed a significant association between the results of the MEM (normal or altered) and FVS and FVF results ( $p<0.01$, for both tests).

The one-way Anova test presented a significant difference for the age factor in the MEM and in FVS $(F 1.23=6.94 ; p<0.01$ and $F 1.23=4.15 ; p=0.03$, respectively), but did not present significant differences regarding FVF ( $F 1.28=2.39 ; p=0.11)$. To verify in which age groups these differences were found, the Tukey Post Hoc test was performed. The test identified that in both MEM and FVS, the difference is evident when comparing individuals aged between 26 to 49 years old with individuals over 66 years of age, as can be seen in Figure 3.

Another factor studied was schooling. Regarding this, the Anova test showed a statistically significant difference in MEM, FVS and FVF (F1,22 = 15,26; $p<0,01 ; F 1,22=4,182 ; p<0,05$ and $F 1,22=$ 4.71; $\mathrm{P}<0.05$, respectively). Tukey's Post Hoc test identified that, in the MEM, the difference occurs when comparing the results of illiterate individuals with literate individuals. In FVS and FVF, the difference was evident when comparing illiterate individuals with individuals with more than four years of study, as can be observed in Figure 3.

\section{DISCUSSION}

A large number of diseases can be associated with cognitive alterations, but the examination of cognitive functions is still usually reserved for patients with complaints in this sphere, more specifically, in the initial evaluation of dementias ${ }^{21,22}$. However, although this study was performed in patients with no complaints related to cognitive functions, a significant number of patients with changes in the tests performed were found.

The significant number of changes observed in this study is far superior to a similar study that evaluated 105 patients, without complaints of cognitive alterations in a general neurology ambulatory. The MEM was altered in $20 \%$ of the patients and the verbal fluency test was below the cut-off scores in $27.6 \%{ }^{21}$. This was possible due to two factors that were isolated or which occurred concurrently. One factor presents a low level of schooling of the studied sample and its effect on the cognitive reserve, since the years of study are directly related to a greater cognitive reserve, indicating a strong influence of schooling on the results of the verbal fluency test $t^{11,23}$. This hypothesis is reinforced by a national study aiming to establish normative standards for verbal fluency tests, in which the authors ${ }^{24}$ observed that the educational variable showed a greater impact, in both evocation modalities, than age.

In addition, although no evaluation scale for depression has been applied in this study, it should be considered that the patients were hospitalized due to different causes. The fact that other researches have already indicated that the prevalence of depression among people with other clinical diseases increases 3 to 5 times, when compared to the general population, should be noted ${ }^{25}$. The frequency of depressive disorders in patients admitted to a general hospital can vary from $10 \%$ to $50 \%$, depending on the services and definitions on depression ${ }^{26,27}$. As is well known ${ }^{28}$, patients diagnosed with depression may present impairment of various cognitive abilities, including psychomotricity, memory, reading comprehension, verbal fluency, and executive functions. Thus, it is possible that hospitalization associated with low schooling may have influenced the poor performance of the studied population.

The difference found when comparing the findings of FVS and FVF in the 15-30 second and 45-60 second blocks agrees with other studies 9,20 , which observed that the highest number of words is generated in the first block of time (0-15 seconds). This happens due to the greater ease of evocation at the beginning of the test, a consequence of the automatic evocation processes and the frequent semantic relation that is established in the first words evoked.

In the VF test, the encephalic areas of greater activation are the frontal lobes in the FVF test, and the temporal lobes in the FVS. These brain activations occur due to the type of strategy used in each task ${ }^{29,30}$. The literature states that in the FVS exists the use of semantic strategies and, in the FVF, there is the use of clues based on lexical representations and orthographic criteria, therefore, it is less usual. This would explain the lower number of words emitted in the FVF test and the strong influence of high schooling in the findings ${ }^{17}$, in accordance with this study.

Several studies have demonstrated the influence not only of schooling, but also of age on cognitive tests. It is known that there is a cognitive decline due to the increase of age, even in healthy and active 
individuals ${ }^{9-15}$. These findings agree with the present study that presented a statistically significant difference when comparing the results of individuals who were in the lower age group with individuals over 65 years old in the MEM and FVS test. In the FVF test, this difference was not observed, suggesting that age is not a decisive factor for performance in this test.

A study that aimed to verify the verbal learning in 200 individuals, without related complaints, submitted to FVS and FVF tests, observed a decrease in the production of words along with increasing age and with a decrease in the level of schooling, presenting the average number of words produced in two groups, adults and elderly, separated by schooling ${ }^{20}$.

In the MEM, the influence of lack of literacy on performance is clearly observed. This result (added to the fact that there was a difference between the groups in the performance of the FVS and FVF tests when comparing literate individuals with the individuals who studied more than four years) made it possible to confirm, as described in the literature, that individuals with some level of schooling present a better performance in the tests ${ }^{8-11}$.

It should be noted that, in normal aging, different memory systems are not affected equally. It is known that changes in non-declarative memory and semantic memory are not expected with increasing age ${ }^{31}$. This fact assists in the differential diagnosis regarding possible dementia and mild cognitive impairment. Thus, the joint use of MEM and VF Test is proposed, increasing the sensitivity of cognitive screening.

The main limitations of the present study were the lack of a control group, which led us to compare the results with the available data for the adult and elderly population and, the reduced number of patients. In addition, because it is a group of patients, it would be important to have performed some evaluation of eventual depressive symptomatology, a factor that may interfere with the performance of the tests performed.

However, the high incidence of cognitive alterations causes the results found to be relevant and demonstrate the importance of new studies confirming the need for a brief cognitive evaluation, routinely, in hospitalized adult and elderly, regardless of whether their complaint is in the cognitive sphere or not.

\section{CONCLUSION}

The results demonstrated the high frequency of cognitive alterations in hospitalized adults and elderly and that the MEM and the FVF and FVS tests were correlated. There was an association between the results of the MEM and the FVS, as well as with the FVF. The effect of age was observed when comparing younger and older individuals in MEM and FVS. Also, the effect of lack of literacy in MEM and the influence of high schooling on performance in FVF and FVS tests were observed.

Therefore, it is important to highlight the importance of cognitive screening in hospitalized patients without related complaints, and that age and schooling are important factors in the cognitive performance of the studied population.

\section{REFERENCES}

1. Soares RM, Diniz AB, Cattuzo MT. Associação entre atividade física, aptidão física e desempenho cognitivo em idosos. Motricidade. 2013;9(2):84-93.

2. Carvalho AFT, Peixoto ERS. Memória na prática da Terapia Ocupacional e da Fonoaudiologia.1 1 ed. Rio de Janeiro: Rubio; 2012.

3. Roth M, Tym E, Mountjoy CQ, Huppert FA, Hendrie $\mathrm{H}$, Verma $\mathrm{S}$ et al. CAMDEX: a standardized instrument for the diagnosis of mental disorder in the elderly with special reference to the early detection of dementia. Br J Psychiatry. 1986;149:698-709.

4. Morris JC, Heyman A, Mohs RC, Hughes JP, van Belle $G$, Fillenbaum $G$ et al. The consortium to establish a registry for Alzheimer's disease (CERAD): I. Clinical and neuropsychological assessment of Alzheimer's disease. Neurology. 1989;39(9):1159-65.

5. Zaudig M, Mittelhammer J, Hiller W, Pauls A, Thora $C$, Morinigo $A$ et al. SIDAM: a structured interview for the diagnosis of dementia of the Alzheimer's type, multi-infarct dementia and dementias of the other etiology according to ICD-10 and DSM-III-R. Psychol Med. 1991;21(1):225-36.

6. Boustani M, Peterson B, Hanson L, Harris R, Lohr KN. Screening for dementia in primary care: a summary of the evidence for the U.S. Preventive Services Task Force. Ann Intern Med. 2003;138(11):927-37.

7. Folstein MF, Folstein SE, McHugh PR. Mini-mental state: A practical method for grading the cognitive state of patients for the clinician. J Psychiatr Res. 1975;12(3):189-98.

8. Brucki S, Nitrini R, Caramelli P, Bertolucci PHF, Okamoto $\mathrm{IH}$. Suggestions for utilization of the mini-mental state examination in Brazil Arq Neuropsiquiatr. 2003;61(3B):777-81. 
9. Lourenço RA, Veras RP. Mini-Mental State Examination: psychometric characteristics in elderly outpatients. Rev Saúde Publica. 2006;40(4):712-9.

10. Brucki SMD, Rocha MS. Category fluency test: effects of age, gender and education on total scores, clustering and switching in Brazilian Portuguese-speaking subjects. Braz J Med Biol Res. 2004;37(12):1771-7.

11. Machado TH, Fichman HC, Santos EL, Carvalho VA, Fialho PP, Koenig AM et al. Normative data for healthy eldery on the phonemic verbal fluency task - FAS. Dement Neursopsychol. 2009;3(1):55-60.

12. Casals-Coll M, Sánchez-Benavides G, Quintana $M$, Manero RM, Rognoni T, Calvo $L$ et al. Estudios normativos españoles en población adulta joven (proyecto NEURONORMA jóvenes): normas para los test de fluencia verbal. Neurología. 2013;28(1):33-40.

13. Opasso PR, Barreto SS, Ortiz KZ. Fluência verbal fonêmica em adultos de alto letramento. Einstein. 2016;14(3):398-402.

14. Santos KPS, Santana APOL. Teste de Fluência Verbal: uma revisão histórico-crítica do conceito de fluência. Distúrb. Comun. 2015;27(4):807-18.

15. Bertolucci PHF, Brucki SMD, Campacci SR, Juliano Y. The Mini-Mental State Examination in a general population: impact of educational status. Arq. Neuropsiquaitria. 1994;52(1):1-7.

16. Brucki SMD, Malheiros SMF, Okamoto IH, Bertolucci PHF. Dados Normativos para o teste de fluência verbal categoria animais em nosso meio. Arq. Neuropsiquaitria. 1997;55(1):56-61.

17. Holsinger $T$, Deveau J, Boustani $M$, Williams JW Jr. Does this patient have dementia? JAMA. 2007;297(21):2391-404.

18. Aprahamian I, Martinelli JE, Rasslan Z, Yassuda MS. Rastreio Cognitivo em Idosos para o Clínico. Rev Bras Clin Med. 2008;6:254-9.

19. Senhorini MC, Amaro Júnior E, de Melo Ayres A, de Simone A, Busatto GF. Phonemic fluency in Portuguese-speaking subjects in Brazil: ranking of letters. J Clin Exp Neuropsychol. 2006;28(7):1191-200.

20. Rodrigues AB, Yamashita ET, Chiappetta ALM. Verbal fluency test in adult and elderly: verification of verbal learning . Rev. CEFAC. 2008;10(4):443- 51.

21. Vitiello APP, Ciríaco JGM, Takahashi DY, Nitrini R, Caramelli P. Avaliação cognitiva breve de pacientes atendidos em ambulatório de neurologia geral. Arq Neuropsiquiatr. 2007;65(2-A):299-303.
22. Bechert M, Irigaray TQ, Tentrini CM. Qualidade de vida, cognição e desempenho nas funções executivas de idosos. Estud. psicol. 2012;29(2):155-62.

23. Zimmermann N, Parente MAMP, Joanette $\mathrm{Y}$, Fonseca RP. Unconstrained, phonemic and semantic verbal fluency: age and education effects, norms and discrepancies. Psicologia: Reflexão e Crítica. 2014;27(1):55-63.

24. Esteves CS, Oliveira CR, Carmen Moret-Tatay C, Navarro-Pardo E, De Carli GA, Silva IG et al. Phonemic and Semantic Verbal Fluency Tasks: Normative Data for Elderly Brazilians. Psicologia Reflexão e Crítica. 2015;28(2):350-5.

25. Bair MJ, Robinson RL, Katon W, Kroenke K. Depression and pain comorbidity: a literature review. Arch Intern Med. 2003;163 (20):2433-45.

26. Marcolino JAM, Mathias LAST, Piccinini Filho L, Guaratini AA, Suzuki FM, Alli LAC. Escala hospitalar de ansiedade e depressão: estudo da validade de critério e da confiabilidade com pacientes no pré-operatório. Rev Bras Anestesiologia. 2007;57(1):52-62.

27. Gioia-Martins DF, Medeiros PCS, Hamzeh SA. Avaliação psicológica de depressão em pacientes internados em enfermaria de hospital geral. Psicologia: teoria e prática. 2009;11(1):128-41.

28. Avila R, Bottino CMC. Atualização sobre alterações cognitivas em idosos com síndrome depressiva. Rev Bras Psiquiatr. 2006;28(4):316-20.

29. Baldo JV, Shimamura AP, Delis DC, Kramer J, Kaplan E. Verbal and design fluency in patients with frontal lobe lesions. J Int Neuropsychol Soc. 2001;7(5):586-96.

30. Troyer AK. Normative data for clustering and switching on verbal fluency tasks. J Clinic Exp Neuropsychol. 2000;22(3):370-8.

31. Yassuda MS, Lasca VB, Neri AL. Meta-memória e auto-eficácia: um estudo de validação de instrumentos de pesquisa sobre memória e envelhecimento. Psicol Reflex Crit. 2005;18(1):78-9. 